\title{
O ESTADO DA ARTE DAS QUESTÕES SOCIOCIENTÍFICAS NO PERÍODO DE 2014 - 2018
}

\section{The State of Art of Social Scientific Issues in the Period 2014 - 2018}

\author{
Cristine Roman Cardoso de Araujo Silva* \\ José Vicente Lima Robaina**
}

\begin{abstract}
Resumo: O presente artigo se propõe a fazer um levantamento das publicações sobre a temática Questões Sociocientíficas (QSC), produzidas entre 2014 até 2018, para a elaboração de um Estado da Arte sobre o tema, utilizando seis bases de dados distintas para subsidiar a busca destas informações. Os descritores considerados para a análise foram QSC, e o seu cruzamento com outros três unitermos: Ciência, Tecnologia, Sociedade e Ambiente (CTSA), Formação de Professores de Ciências e Educação em Ciências. A metodologia utilizada para a escolha dos trabalhos selecionados foi a análise por meio da leitura de todos os títulos e palavras-chave, verificando se havia relevância para a pesquisa, após como segunda forma de classificação passou-se a leitura dos resumos e em terceira etapa, houve então, a leitura do trabalho completo. Concluímos que não foram encontrados trabalhos que trouxessem o cruzamento dos quatros unitermos (QSC, CTSA, Formação de Professores de Ciências e Educação em Ciências), houve no máximo trabalhos que traziam apontamentos sobre duas ou três das temáticas articuladas, mas alguma publicação que incorporasse as quatro não foi encontrado, o que torna ainda mais instigante e oportuna a proposta de pesquisa da qual este artigo é parte integrante, que é o de reconhecer e compreender se a formação docente dos professores de Ciências da Natureza permite aos mesmos que proponham suas aulas utilizando as QSC com enfoque na Educação CTSA, para a melhoria da capacidade de mobilização de conteúdos e da formação de cidadãos críticos e responsáveis pela sociedade da qual são parte integrante.
\end{abstract}

Palavras chave: Questões Sociocientíficas. CTS/CTSA. Formação de Professores de Ciências. Educação em Ciências.

Abstract: This article intends to investigate publications on Socio-scientific Issues (SSI), produced between 2014 to 2018, for the elaboration of a State of the Art on the

\footnotetext{
* Doutoranda do Programa de Pós-Graduação em Educação em Ciências: Química da Vida e Saúde da Universidade Federal do Rio Grande do Sul - UFRGS. https://orcid.org/0000-0002-9402-4710. E-mail: cristine@mecinformatica.inf.br

** Doutor em Educação pela Universidade do Vale do Rio do Sinos - UNISINOS. Professor do Curso de Licenciatura em Educação do Campo - EDUCAMPO; Professor do Programa de Pós-Graduação em Educação em Ciências - PPGEC - UFRGS; Professor do Programa de Pós-Graduação em Educação em Ciências e Matemática da Rede Amazônica de Educação em Ciências - REAMEC; Coordenador do Grupo de Pesquisa em Educação do Campo e Ciências da Natureza - GPEEC NATUREZA. https://orcid.org/00000002-4604-3597. E-mail: joserobaina1326@gmail.com e jose.robaina@ufrgs.br.
} 
theme, using six different databases to support the search for this information. The descriptors considered for the analysis were SSI, and their crossing with three other terms: Science, Technology, Society and Environment (STSE), Science Teacher Education and Science Education. The methodology used to choose the selected academic papers was the analysis by reading all the titles and keywords, checking if there was relevance to the research, after reading the abstracts as a second form of classification and in a third step , then, there was the reading of the complete academic work. We concluded that no studies were found that brought the crossing of the four terms (SSI, STSE, Science Teacher Education and Science Education), there were among most of the works that brought notes on two or three of the articulated themes, however some publication that incorporated the four was not found, which makes the research proposal of which this article is an integral part even more instigating and opportune, that is to recognize and understand if the teacher education of Natural Sciences teachers allows them to propose their classes using SSI with a focus on STSE Education, to improve the ability to mobilize content and form critical citizens and those responsible for the society of which they are an integral part.

Keywords: Socio-scientific issues. STS. Science Teacher Training. Science Education.

\section{Introdução}

As Questões Sociocientíficas ${ }^{1}$ ou Controvérsias Sociocientíficas como também são chamadas, manifestam-se nos debates difundidos pela mídia. As QSC estão presentes em questões políticas, ambientais e sociais, por exemplo, e, consequentemente nos currículos escolares, pois atuam como uma forma de dialogar / entender os dilemas sociais relacionados às ordens científicas e tecnológicas.

Ao final da década de 1980, em virtude do progresso científico-tecnológico de pesquisas relacionadas com as áreas da genética, biotecnologia e engenharia genética, fez-se necessário admitir a bioética como campo de estudo, e como resultado conferiu-se maior destaque a inserção das QSC no currículo do Ensino de Ciências.

De modo histórico, de acordo com Levinson (2006), as discussões que trazem temas controversos se instituíram no contexto escolar de início levantando temáticas de cunho mais social, não envolvendo necessariamente tópicos relacionados à ciência e à tecnologia. As discussões sociocientíficas, por sua vez, estão diretamente conectadas a temas relacionados às ciências e a tecnologia.

Segundo Oulton, Dillon e Grace (2004), no que se refere à historicidade da inserção das QSC nos currículos, considerando seus campos investigativo e pedagógico, o autor diz que "para além da repetição da necessidade de se ensinar ciências em um contexto mais amplo, o objetivo era fazer com que os discentes pudessem entender a natureza das questões controversas. De acordo com Sadler (2004), a utilização das QSC traduz o propósito de habilitar os discentes a tomarem decisões sobre questões sociais da nossa contemporaneidade, o que implica em colocar em evidência aspectos morais conectados em contextos científicos. Nesta conjuntura, o discente é conduzido a não só

\footnotetext{
${ }^{1}$ Neste artigo será utilizada a sigla QSC para nomear tanto o que os autores chamam de questões sociocientíficas, como também controvérsias sociocientíficas.
} 
interpretar problemas buscando diferentes pontos de vista, como também pensar em sua argumentação nas áreas científica, moral e social.

São definidas como QSC do tipo questões abertas as perguntas cujas soluções são indeterminadas ou variadas (SILVA, 2014, p. 19). Elas abrangem conceitos científicos associados a valores, concepções e práticas, o que lhes dá um caráter controverso. Em consequência, suas respostas, quando existem, ponderam uma série de outros aspectos ligados a ciência. Este caráter multifacetado torna as QSC potenciais aliadas para o progresso de competências argumentativas junto aos discentes quando trabalhadas em sala de aula, porque funcionam como "catalisadoras de debates" (BERNARDO, 2013). Por sua vez, as atividades didáticas e pedagógicas que seguem os preceitos das QSC instigam e proporcionam o desenvolvimento intelectual dos discentes, principalmente no que tange as relações morais e éticas, além de contribuírem para a compreensão a respeito das relações entre CTSA (SILVA, 2014, p. 21).

Como consequência, de acordo com autores como Sadler (2004), por exemplo, as QSC não se reduzem a servir como um contexto para a aprendizagem de conteúdos científicos, mas também podem ser vistas como um método pedagógico com objetivos nitidamente definidos. ZEIDLER et al. (2005 apud Silva, 2014, p. 21), apontam, QSC é um termo amplo que abarca tudo o que a concepção CTSA tem a oferecer para o ensino, além de conceber as dimensões éticas da ciência, o raciocínio moral e o progresso emocional do discente. Nesse sentido, Tal e Kedmi (2006) creem que ações educativas baseadas em questões sociocientíficas seriam capazes de desenvolver competências junto aos discentes que melhorem a análise crítica de informações, resolução de problemas, argumentação, o pensamento reflexivo e juízos de valor.

A Educação na perspectiva da Ciência, Tecnologia, Sociedade e Ambiente $(\mathrm{CTSA})^{2}$ traz o embasamento necessário às QSC, pois leva em consideração as propostas de temas controversos conduzindo a um objetivo específico. Neste sentido, a relação entra as QSC e a Educação CTSA se dá por meio da emergência de discussões de natureza controversa apoiadas em valores éticos e morais.

Silva (2016), aponta a relação existente entre as QSC com o enfoque CTSA, sendo estas evidenciadas pelos objetivos comuns às duas temáticas (Figura 1). Assim, entendese que as especificidades à abordagem das QSC habitam na caracterização de objetivos específicos como a elucidação de valores; o raciocínio ético e moral; a argumentação; o engajamento para tomada de decisões; as limitações do conhecimento técnico; as incertezas; e a natureza multidisciplinar.

Percebe-se então, que as QSC têm se firmado como uma dimensão mais específica da Educação CTSA, todavia, mesmo que as QSC sejam provenientes das aplicações da Educação CTSA, possuem também seus objetivos próprios. Desta forma, complementam-se frente a uma mesma finalidade voltada à educação científica, buscando a formação de cidadãos aptos para atuarem em uma sociedade democrática.

\footnotetext{
${ }^{2}$ Mesmo quando a palavra Ambiente não está aparente na sigla CTS (Ciência Tecnologia e Sociedade), seu conceito continua implícito, visto que para os autores que falam sobre o assunto, o Ambiente não está desprendido da Sociedade, pois a Sociedade está contida no Ambiente e não desagregada dele. Sendo assim, para este artigo, adota-se o uso da sigla CTSA.
} 
Figura 1 - Representação da Complementariedade Objetiva Específica CTSA-QSC

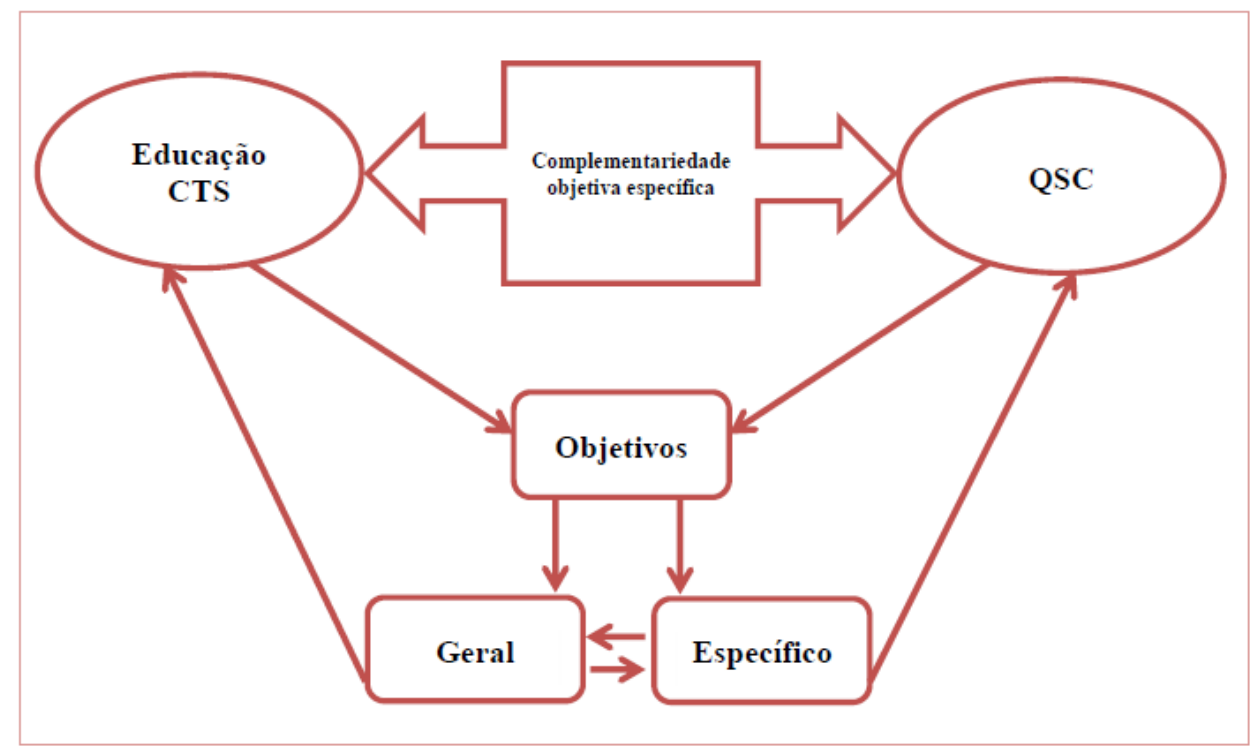

Fonte: (SILVA, 2016)

Tendo como propósito integral, que se pretende alcançar em pesquisa mais ampla a qual se fará dentro em breve, sendo o de reconhecer e compreender se a formação docente dos professores de Ciências da Natureza ${ }^{3}$, permite que esses proponham suas aulas utilizando as QSC com enfoque na Educação CTSA, para a melhoria da capacidade de mobilização de conteúdos e da formação de cidadãos socioambientalmente responsáveis no contexto do Ensino Médio, é que se produziu esta pesquisa em forma de Estado da Arte, para identificar aquilo que já foi publicado sobre este assunto (QSC) e apurar se já existe alguma publicação que faça a relação completa entre QSC no enfoque da Educação CTSA com a formação dos professores de Ciências da Natureza.

\section{Percurso metodológico: a construção do Estado da Arte}

Trata-se de uma pesquisa com caráter quali-quantitativo, pois, de acordo com Baptista (1999, p. 34), a análise qualitativa dos dados quantitativos busca "uma síntese unificadora do conhecimento". O estudo é caracterizado como estado da arte, o qual objetiva inventariar, sistematizar e avaliar a produção em determinada área do conhecimento em um período previamente estabelecido (MEGID NETO, 1999). Esse tipo de pesquisa dá maior visibilidade às produções realizadas, permite uma reflexão crítica sobre estas e possibilita o acesso e a utilização das experiências enunciadas (GAMBOA, 1987).

Foram utilizadas seis bases de dados para subsidiar o levantamento do material analisado nesta pesquisa. Para isto, utilizou-se as seguintes etapas: a) seleção das bases de dados: elegeu-se para a busca dos dados desta pesquisa a Biblioteca Digital Brasileira de Teses e Dissertações (BDTD); o Catálogo de Teses e Dissertações Capes (CTDC), a Biblioteca Eletrônica Científica Online (SciELO), os anais do Encontro Nacional de Pesquisa em Educação em Ciências (ENPEC), a Revista Brasileira de Pesquisa em

\footnotetext{
${ }^{3}$ Entende-se por professores de Ciências da Natureza, os licenciados em Química, Física e Biologia.
} 
Educação em Ciências (RBPEC) e no Google Acadêmico. A escolha destas bases de dados se deve a sua relevância à área de Ensino de Ciências. b) seleção dos dados: utilizou-se em todas as bases pesquisadas a busca do unitermo Questões sociocientíficas; nas bases BDTD e CTDC, selecionou-se adicionalmente como fator limitador os campos de busca "área de conhecimento" (Ensino de Ciências e Matemática) e "área de concentração" (Educação em Ciências); na SciELO, anais do ENPEC, RBPEC e no Google Acadêmico, utilizou-se o campo de busca principal. Inicialmente foram selecionados todos os documentos resultados da busca. Posteriormente, para um refinamento dos dados, optou-se também pela busca do unitermo fazendo seu cruzamento com os outros três unitermos: CTSA, Formação de Professores de Ciências e Educação em Ciências. Outro critério foi que o material analisado deveria constar dentro do período de 2014 a 2018, exceto os anais ENPEC, que por se tratar de um evento bianual, utilizouse os documentos no período compreendido entre 2013 e 2017.

Cabe destacar que na etapa da pesquisa feita na CTDC onde se fez o cruzamento dos unitermos QSC e Formação de Professores de Ciências, em um primeiro momento houve o surgimento de um número de trabalhos inviável de ser analisado, muitos dos quais se desviavam completamente do propósito que se desejava alcançar. Por esta razão e para que os resultados encontrados não se afastassem do objetivo que se propõe esta pesquisa utilizou-se como refinamento da busca, nesta base de dados, os seguintes parâmetros, a saber: tipo doutorado, período 2014 até 2018, área de conhecimento Ensino de Ciências e matemática e área de concentração Ensino de Ciências e matemática.

Nesta fase da pesquisa onde se realizou o cruzamento dos unitermos QSC e Educação em Ciências, ocorreu o mesmo obstáculo enfrentado no cruzamento acima descrito, ou seja, existiu o surgimento de um número de trabalhos impraticável de serem analisados, então para que os resultados encontrados na CTDC não se distanciassem do que se propõe utilizou-se como refinamento da busca, nesta base de dados, os seguintes parâmetros, a saber: tipo doutorado, período 2014 até 2018, área de conhecimento Ensino de Ciências e matemática e área de concentração Ensino de Ciências e matemática.

Dos trabalhos selecionados na busca inicial, prosseguimos com o processo de filtragem para chegar ao Estado da Arte das pesquisas sobre QSC e posteriormente do seu cruzamento com os outros três unitermos, conforme mencionado no parágrafo acima. Para isso, primeiramente realizou-se uma seleção por meio da leitura de todos os títulos e palavras-chave evidenciados através da busca, verificando se havia nesta alguma relevância para a pesquisa trazendo evidências dos unitermos destacados. Como segunda forma de classificação passou-se a leitura dos resumos e em terceira escala de análise e classificação, houve então, a leitura do trabalho completo.

\section{Apresentação dos dados e discussão}

Como resultado das buscas nas bases de dados utilizando os critérios descritos nos procedimentos metodológicos desta pesquisa, registrou-se a ocorrência de 202 trabalhos por assunto. Após a leitura do resumo e, posteriormente, a leitura completa do trabalho, selecionou-se 40 trabalhos que apresentavam aspectos relacionados com o uso das QSC no Ensino de Ciências. A Tabela 1 e a Figura 2 sintetizam os resultados obtidos nas buscas realizadas nas bases de dados e o número de trabalhos selecionados após leitura dos resumos e leitura na íntegra. 


\section{; tear}

Revista de Educação, Ciência e Tecnologia

Tabela 1 - Relação de trabalhos encontrados nas bases de dados pesquisadas sobre a temática QSC

\begin{tabular}{cccc}
\hline Fonte & Trabalho por assunto & $\begin{array}{c}\text { Trabalhos após } \\
\text { leitura do resumo }\end{array}$ & $\begin{array}{c}\text { Trabalhos após } \\
\text { leitura completa }\end{array}$ \\
\hline BDTD & 36 & 10 & 08 \\
CTDC & 19 & 08 & 06 \\
Scielo & 03 & 01 & 00 \\
Google Acadêmico & 82 & 32 & 18 \\
ENPEC & 59 & 09 & 08 \\
RBPEC & 03 & 01 & 00 \\
Total & 202 & 61 & 40 \\
\hline
\end{tabular}

Fonte: Elaborado pelos autores (2020).

Figura 2 - Gráfico da Produção Acadêmica sobre a temática QSC nas bases pesquisadas

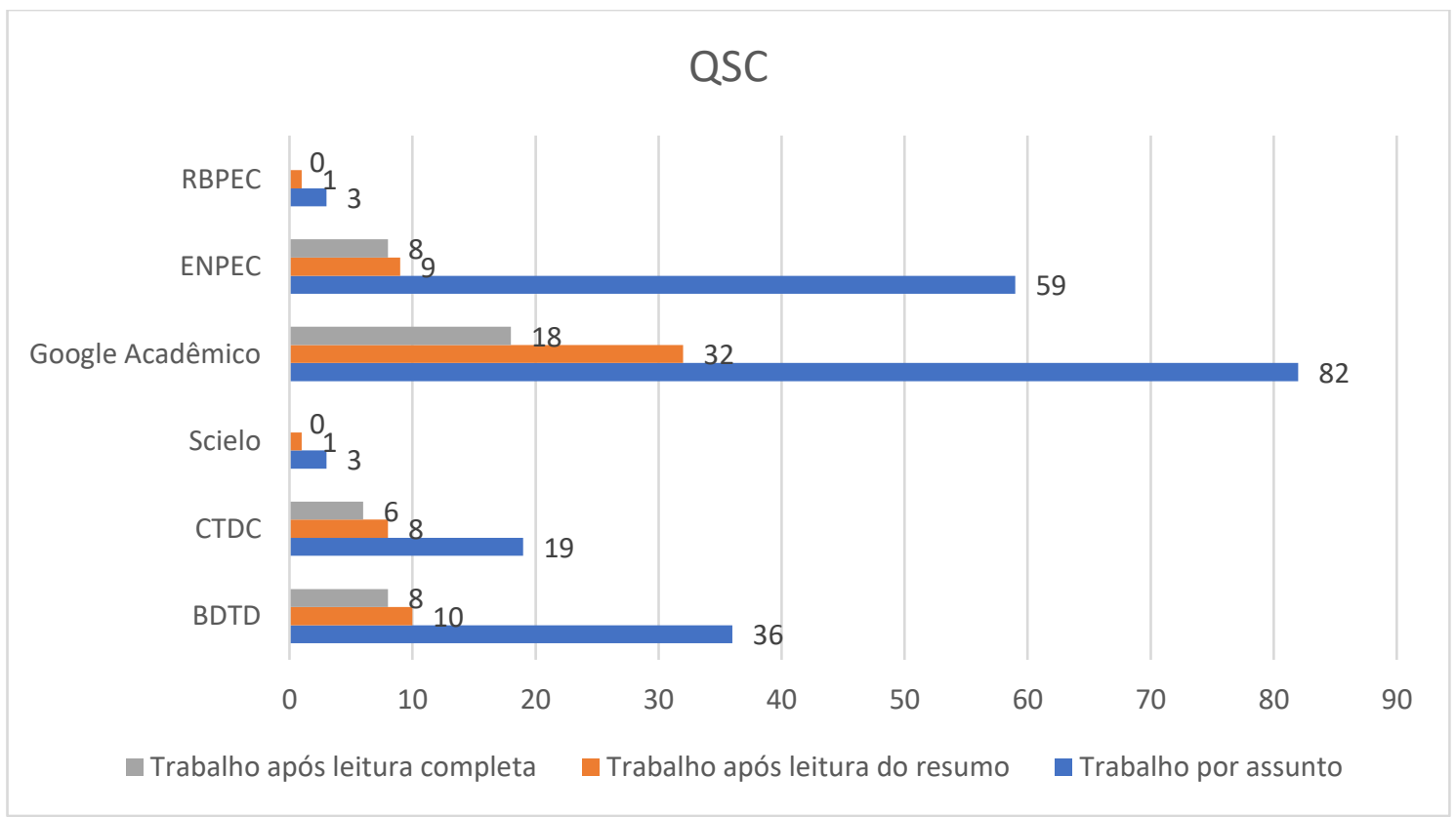

Fonte: Elaborado pelos autores (2020).

Constatou-se no Google Acadêmico um número expressivo de publicações referentes às QSC, em comparação às outras bases de dados pesquisadas, representando 18 trabalhos dos 40 selecionados. O Quadro 1 apresenta uma síntese dos trabalhos selecionados por meio do Google Acadêmico, evidenciando o título da produção, ano de publicação e seus autores.

Quadro 1 - Relação de trabalhos selecionados no Google Acadêmico que tratam sobre a temática QSC

\begin{tabular}{|l|l|}
\hline \multicolumn{1}{|c|}{ Trabalho Selecionado após Leitura Completa } & \multicolumn{1}{|c|}{ Ano de Publicação - Autores } \\
\hline $\begin{array}{l}\text { O tratamento de questões sociocientíficas na formação de professores de } \\
\text { ciências: possibilidades e desafios nas vozes dos licenciandos - Artigo } \\
\text { (Uni-pluri / versidad - Universidad de Antioquia) }\end{array}$ & $\begin{array}{l}\text { 2014 - Michel Pisa Carnio; Washington Luiz } \\
\text { Pacheco de Carvalho }\end{array}$ \\
\hline $\begin{array}{l}\text { Compreensões sobre a natureza da ciência de licenciandos a partir da } \\
\text { experiência com questões sociocientíficas: possibilidades para a } \\
\text { formação inicial - Tese }\end{array}$ & 2015 - Diana Fabiola Moreno Sierra \\
\hline
\end{tabular}


Formação docente relacionada com questões sociocientíficas: complexidade, contribuições e limitações de uma prática educativa Artigo (Amazônia - Revista de Educação em Ciências e Matemática)

A discussão de controvérsias sociocientíficas: uma perspectiva integradora no Ensino de Ciências - Tese

A moral em questões sociocientíficas no ensino de biologia - Tese

Questões sociocientíficas na sala de aula de ciências no ensino fundamental na perspectiva do agir comunicativo - Dissertação

Produção de significados por professores de ciências sobre currículo centrado em questões sociocientíficas: contribuições para a formação do professor pesquisador - Artigo (Revista Tecné, Episteme y Didaxis)

Questões sociocientíficas e a gestão democrática na formação inicial e continuada de professores: as potencialidades na Web 2.0. - Dissertação

Análise de um processo de formação continuada de professores de ciências para a abordagem de questões sociocientíficas - Artigo (Revista de Investigación y Experiencias Didácticas)

Proposta CTS para abordar questões sociocientíficas com estudantes de licenciatura através de discussões acerca dos desastres de Fukushima e Mariana - Dissertação

Controvérsias sociocientíficas e projetos integrados: condicionantes e potencialidades para o Ensino de Ciências - Artigo (Revista de Investigación y Experiencias Didácticas)

Abordagem de questões sociocientíficas na prática docente: análise de planos de aulas de jovens professores - Artigo (XI ENPEC)

Questões sociocientíficas na educação CTSA: contribuições de um modelo teórico para o letramento científico crítico - Tese

As controvérsias sociocientíficas no desenho de propostas didáticas como estratégia para a inovação na aula de ciências no contexto da formação inicial de professores - Artigo (Revista Tecné, Episteme y Didaxis)

O ensino de biologia a partir do estudo das doenças autoimunes como controvérsias sociocientíficas: uma proposta didática - Artigo (Revista de Produtos Educacionais e Pesquisas em Ensino

Formação de conceitos da termoquímica em meio a relações CTSA e questões sociocientíficas: contribuições da teoria da atividade históricocultural - Tese

Propostas de ensino baseado em questões sociocientíficas: uma análise sistemática da literatura acerca do Ensino de Ciências na educação básica - Dissertação

Argumentação e raciocínio moral em questões sociocientíficas na formação de professores de ciências: o exemplo da eutanásia Dissertação

Fonte: Elaborado pelos autores (2020).
2015 - Mariuce Campos de Moraes; Diana Claudia Naman; Marta Maria Pontim Darsie

2015 - Leandro Duso

2016 - Shirley Margareth Buffon da Silva

2016 - Ana Maria Teixeira

2016 - Natalia Katherine García Ramírez

2016 - Graciella Watanabe

2017 - Wilka Karla Martins do Vale; Ruth do Nascimento Firme

2017 - Samanda Helena de Freitas Oniesko

2017 - Leandro Duso; Sylvia Regina Pedrosa Maestrelli

2017 - Barbara Simiramis Toledo Martins; Mirian Pacheco Silva

2017 - Dália Melissa Conrado

2018 - Laísa Maria Freire; Mariana Brück; Sama de Freitas Juliani; Raquel Moniz Benac

2018 - Vanessa, Rechetzki; Rodrigo Diego de Souza

2018 - Beatriz Vivian Schneider-Felicio

2018 - Grégory Alves Dionor

2018 - Mayara Tavares de Almeida

O Quadro 2 apresenta a síntese de produções selecionada a partir das buscas realizadas nas fontes BDTD, CTDC e nos anais do ENPEC.

Quadro 2 - Relação de trabalhos escolhidos na BDTD, CTDC e anais do ENPEC que tratam sobre a temática QSC

\begin{tabular}{|l|l|}
\hline \multicolumn{1}{|c|}{ Trabalho Selecionado após Leitura Completa } & $\begin{array}{l}\text { Base de Dados - Ano de Publicação - } \\
\text { Autores }\end{array}$ \\
\hline $\begin{array}{l}\text { O enfoque CTS na formação de professores de ciências e a abordagem } \\
\text { de questões sociocientíficas - Artigo }\end{array}$ & $\begin{array}{l}\text { IX ENPEC - 2013 - Rosa Oliveira Marins } \\
\text { Azevedo; Evandro Ghedin; Maria Clara da } \\
\text { Silva Forsberg; Amarildo Menezes Gonzaga }\end{array}$ \\
\hline $\begin{array}{l}\text { Agrotóxicos - toxidade versus custos: uma experiência de formação de } \\
\text { professores com as questões sociocientíficas no Ensino de Ciências - } \\
\text { Artigo }\end{array}$ & $\begin{array}{l}\text { IX ENPEC - 2013 - Nataly Carvalho Lopes; } \\
\text { Washington Luiz Pacheco de Carvalho; } \\
\text { Paulo Cézar de Faria }\end{array}$ \\
\hline
\end{tabular}


O tratamento de questões sociocientíficas na educação científica: pressupostos, práticas escolares e formação de professores - Artigo O tratamento de questões sociocientíficas na formação de professores de ciências: possibilidades e desafios nas vozes dos licenciandos - Artigo A história dominante do movimento CTS e o seu papel no subcampo brasileiro de pesquisa em Ensino de Ciências CTS - Artigo

Abordagem de temas sociocientíficos em periódicos nacionais de Ensino de Ciências publicados no período de 2005-2014 - Artigo

Compreensões sobre a natureza da ciência de licenciandos a partir da experiência com questões sociocientíficas: possibilidades para a formação inicial - Tese

A discussão de controvérsias sociocientíficas: uma perspectiva integradora no Ensino de Ciências - Tese

Produção de significados por professores de ciências sobre currículo centrado em questões sociocientíficas: contribuições para a formação do professor pesquisador - Dissertação

A moral em questões sociocientíficas no ensino de biologia - Tese

Abordagem de questões sociocientíficas na prática docente: análise de planos de aulas de jovens professores - Artigo

Os créditos de carbono e suas relações com o consumo como questões sociocientíficas no Ensino de Ciências - Artigo

Um olhar sobre os processos de apropriação e objetivação da abordagem de questões sociocientíficas na formação de professores de ciências naturais - Dissertação

Questões sociocientíficas na educação CTSA: contribuições de um modelo teórico para o letramento científico crítico - Tese

Formação de conceitos da termoquímica em meio a relações CTSA e questões sociocientíficas: contribuições da teoria da atividade históricocultural - Tese

Propostas de ensino baseado em questões sociocientíficas: uma análise sistemática da literatura acerca do Ensino de Ciências na educação básica - Dissertação

Argumentação e raciocínio moral em questões sociocientíficas na formação de professores de ciências: o exemplo da eutanásia Dissertação

As percepções e apropriações da perspectiva CTS e da abordagem de QSC no processo de formação docente - Tese

Fonte: Elaborado pelos autores (2020).

Pelos dados relacionados no quadro 2, observa-se que dos oito trabalhos selecionados para pesquisa na BDTD, sete deles também constam na lista daqueles encontrados no Google Acadêmico. Dos seis trabalhos da CTDC, três deles foram encontrados tanto na BDTD quanto no Google acadêmico; e dos 03 trabalhos restantes, um consta também no Google Acadêmico, um está contido na BDTD, e um foi encontrado somente na CTDC. Dos 08 trabalhos selecionados nos anais do ENPEC, 02 deles também foram localizados pelo Google Acadêmico. Todo o exposto corrobora a escolha e a utilização destes trabalhos.

Em uma segunda etapa de refinamento, ao cruzar-se os unitermos QSC e CTSA foram obtidos 36 trabalhos que, após a leitura dos resumos e, posteriormente a leitura completa dos trabalhos, elegeu-se apenas três trabalhos atendendo os critérios desta pesquisa, sendo estes publicados nos anais do ENPEC. A síntese dos dados obtidos nas pesquisas realizadas nas bases de dados, cruzando os unitermos QSC e CTSA pode ser observada na Tabela 2 e figura 3. 
Tabela 2 - Relação de trabalhos encontrados no cruzamento dos unitermos QSC e CTSA

\begin{tabular}{cccc}
\hline Fonte & Trabalho por assunto & $\begin{array}{c}\text { Trabalhos após } \\
\text { leitura do resumo }\end{array}$ & $\begin{array}{c}\text { Trabalhos após } \\
\text { leitura completa }\end{array}$ \\
\hline BDTD & 01 & 00 & 00 \\
CTDC & 29 & 01 & 00 \\
SciELO & 01 & 00 & 00 \\
Google & 00 & 00 & 00 \\
ENPEC & 03 & 03 & 03 \\
RBPEC & 02 & 00 & 00 \\
Total & 36 & 04 & 03 \\
\hline
\end{tabular}

Fonte: Elaborado pelos autores (2020).

Figura 3 - Gráfico obtido por meio do cruzamento dos unitermos QSC e CTSA nas bases pesquisadas

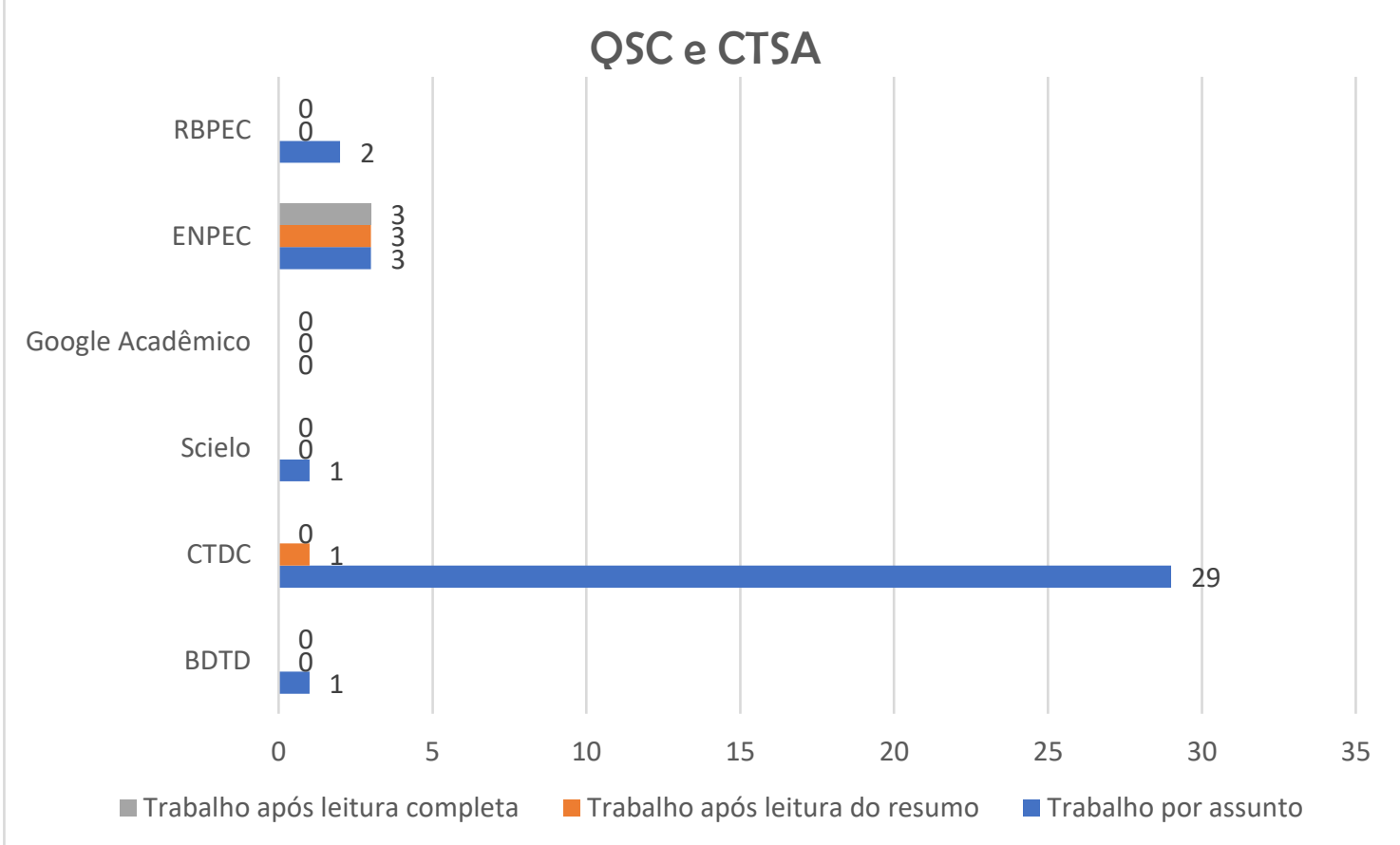

Fonte: Elaborado pelos autores (2020).

As questões sociocientíficas (QSC) têm sido adotadas, nas últimas décadas, na Educação em Ciências para abordar relações entre ciência, tecnologia, sociedade e ambiente (CTSA), com diferentes objetivos de ensino e de aprendizagem. As QSC têm como principais características a abordagem de assuntos tratados com frequência na mídia e a inclusão de elementos de pesquisa científica e tecnológica que implicam questionamentos socioambientais e/ou éticos. (MARTÍNEZ PÉREZ, 2012). Tendo em vista o exposto, buscamos uma educação com enfoque CTSA, por meio de QSC, como parte de uma formação social e política, para uma participação ativa crítica do estudante na sociedade. Por este motivo, relacionamos os trabalhos que se mostraram mais relevantes, aqueles que trouxeram em seu conteúdo as evidências da relação entre QSC e CTSA, como pode ser observado no Quadro 3. 
Quadro 3 - Relação de trabalhos obtidos pelo cruzamento dos unitermos QSC e CTSA

\begin{tabular}{|l|c|}
\hline \multicolumn{1}{|c|}{ Trabalho Selecionado após Leitura Completa - ENPEC } & $\begin{array}{c}\text { Edição do ENPEC - Ano de } \\
\text { Publicação }\end{array}$ \\
\hline $\begin{array}{l}\text { O Enfoque CTS na Formação de Professores de Ciências e a Abordagem } \\
\text { de Questões Sociocientíficas }\end{array}$ & IX ENPEC - 2013 \\
\hline $\begin{array}{l}\text { As Interfaces Entre a Abordagem CTS e as Questões Sociocientíficas } \\
\text { nas Pesquisas em Educação em Ciências }\end{array}$ & IX ENPEC - 2013 \\
\hline $\begin{array}{l}\text { A História Dominante do Movimento CTS e o seu Papel no Subcampo } \\
\text { Brasileiro de Pesquisa em Ensino de Ciências CTS }\end{array}$ & X ENPEC - 2015 \\
\hline
\end{tabular}

Fonte: Elaborado pelos autores (2020).

Quanto ao cruzamento dos unitermos QSC e Formação de Professores de Ciências, foram obtidos 282 trabalhos que agregam estas temáticas, sendo que, após a leitura dos resumos, elegeu-se 14 trabalhos, que salientam tópicos relacionados diretamente com esta pesquisa, dos quais realizou-se a leitura completa. A síntese dos dados obtidos a partir do cruzamento destes unitermos pode ser observada na tabela $3 \mathrm{e}$ na figura 4.

Tabela 3 - Trabalhos encontrados no cruzamento dos unitermos QSC e Formação de Professores de Ciências

\begin{tabular}{cccc}
\hline Fonte & Trabalho por assunto & $\begin{array}{c}\text { Trabalhos após } \\
\text { leitura do resumo }\end{array}$ & $\begin{array}{c}\text { Trabalhos após } \\
\text { leitura completa }\end{array}$ \\
\hline BDTD & 15 & 06 & 06 \\
CTDC & 237 & 12 & 03 \\
Scielo & 00 & 00 & 00 \\
Google & 01 & 01 & 00 \\
ENPEC & 28 & 05 & 05 \\
RBPEC & 01 & 00 & 00 \\
Totais & 282 & 24 & 14 \\
\hline
\end{tabular}

Fonte: Elaborado pelos autores (2020).

Figura 4 - Gráfico do cruzamento dos unitermos QSC e Formação de Professores de Ciências segundo as bases pesquisadas

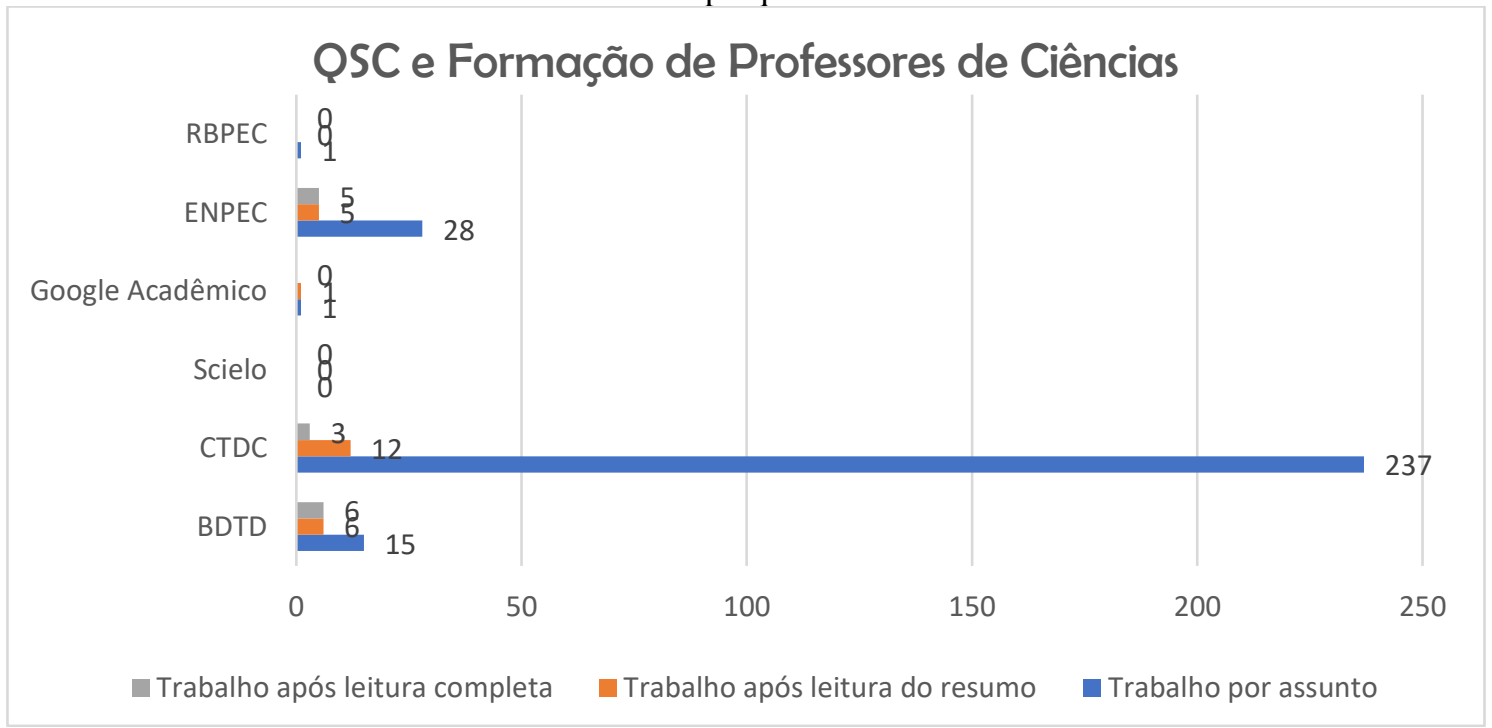

Fonte: Elaborado pelos autores (2020). 
Dos trabalhos, a partir do cruzamento dos unitermos QSC e Formação de Professores de Ciências, obteve-se a seleção das seguintes produções (Quadro 4):

Quadro 4 - Relação de trabalhos escolhidos sobre a temática

\begin{tabular}{|c|c|}
\hline Trabalhos Selecionados após Leitura Completa & $\begin{array}{c}\text { Base de Dados - Ano de Publicação - } \\
\text { Autores }\end{array}$ \\
\hline $\begin{array}{l}\text { O enfoque CTS na formação de professores de ciências e a abordagem } \\
\text { de questões sociocientíficas - Artigo }\end{array}$ & $\begin{array}{l}\text { IX ENPEC - } 2013 \text { - Rosa Oliveira Marins } \\
\text { Azevedo; Evandro Ghedin; Maria Clara da } \\
\text { Silva Forsberg; Amarildo Menezes Gonzaga }\end{array}$ \\
\hline $\begin{array}{l}\text { Agrotóxicos - toxidade versus custos: uma experiência de formação de } \\
\text { professores com as questões sociocientíficas no Ensino de Ciências - } \\
\text { Artigo }\end{array}$ & $\begin{array}{l}\text { IX ENPEC - } 2013 \text { - Nataly Carvalho Lopes; } \\
\text { Washington Luiz Pacheco de Carvalho; } \\
\text { Paulo Cézar de Faria }\end{array}$ \\
\hline $\begin{array}{l}\text { O tratamento de questões sociocientíficas na educação científica: } \\
\text { pressupostos, práticas escolares e formação de professores - Artigo }\end{array}$ & $\begin{array}{l}\text { IX ENPEC - } 2013 \text { - Michel Pisa Carnio; } \\
\text { Wildson Luiz Pereira dos Santos }\end{array}$ \\
\hline $\begin{array}{l}\text { O tratamento de questões sociocientíficas na formação de professores de } \\
\text { ciências: possibilidades e desafios nas vozes dos licenciandos - Artigo }\end{array}$ & $\begin{array}{l}\text { IX ENPEC - } 2013 \text { - Michel Pisa Carnio; } \\
\text { Washington Luiz Pacheco de Carvalho }\end{array}$ \\
\hline $\begin{array}{l}\text { Compreensões sobre a natureza da ciência de licenciandos a partir da } \\
\text { experiência com questões sociocientíficas: possibilidades para a } \\
\text { formação inicial - Tese }\end{array}$ & $\begin{array}{l}\text { BDTD e CTDC - } 2015 \text { - Diana Fabiola } \\
\text { Moreno Sierra }\end{array}$ \\
\hline A moral em questões sociocientíficas no ensino de biologia - Tese & $\begin{array}{l}\text { BDTD - } 2016 \text { - Shirley Margareth Buffon da } \\
\text { Silva }\end{array}$ \\
\hline $\begin{array}{l}\text { Um olhar sobre os processos de apropriação e objetivação da abordagem } \\
\text { de questões sociocientíficas na formação de professores de ciências } \\
\text { naturais - Dissertação }\end{array}$ & $\begin{array}{l}\text { BDTD - } 2017 \text { - Wilka Karla Martins do } \\
\text { Vale }\end{array}$ \\
\hline $\begin{array}{l}{ }^{4} \text { As questões sociocientíficas na formação de professores: o pequeno } \\
\text { grupo de pesquisa como comunidade de experiência - Tese }\end{array}$ & $\begin{array}{l}\text { CTDC - } 2017 \text { - Paulo Gabriel Franco dos } \\
\text { Santos }\end{array}$ \\
\hline $\begin{array}{l}\text { Questões sociocientíficas na educação CTSA: contribuições de um } \\
\text { modelo teórico para o letramento científico crítico - Tese }\end{array}$ & BDTD - 2017 - Dália Melissa Conrado \\
\hline $\begin{array}{l}\text { Abordagem de questões sociocientíficas na prática docente: análise de } \\
\text { planos de aulas de jovens professores - Artigo }\end{array}$ & $\begin{array}{l}\text { XI ENPEC - } 2017 \text { - Barbara Simiramis } \\
\text { Toledo Martins; Mirian Pacheco Silva }\end{array}$ \\
\hline $\begin{array}{l}\text { Formação de conceitos da termoquímica em meio a relações CTSA e } \\
\text { questões sociocientíficas: contribuições da teoria da atividade histórico- } \\
\text { cultural - Tese }\end{array}$ & $\begin{array}{l}\text { BDTD - } 2018 \text { - Beatriz Vivian Schneider- } \\
\text { Felicio }\end{array}$ \\
\hline $\begin{array}{l}\text { Argumentação e raciocínio moral em questões sociocientíficas na } \\
\text { formação de professores de ciências: o exemplo da eutanásia - } \\
\text { Dissertação }\end{array}$ & BDTD - 2018 - Mayara Tavares de Almeida \\
\hline $\begin{array}{l}{ }^{5} \text { Abordagem de questões sociocientíficas: buscando relações entre } \\
\text { diferentes modos de pensar e contextos em estudos sobre fármacos } \\
\text { e automedicação no ensino de química - Tese }\end{array}$ & $\begin{array}{l}\text { CTDC - 2018 - Bruna Herculano da Silva } \\
\text { Bezerra }\end{array}$ \\
\hline
\end{tabular}

Fonte: Elaborado pelos autores (2020).

Dos 13 trabalhos acima referidos, 12 deles já foram anteriormente mencionados e apenas dois aparecem de forma inédita na pesquisa.

Em livro publicado por Martínez-Pérez (2012) intitulado "QSC na prática docente - Ideologia, Autonomia e Formação de Professores", foram reconhecidas evidências práticas que indicam as QSC como uma forma concreta de favorecer a formação cidadã tanto de educadores como de educandos. Os pesquisadores afirmam ter ocorrido renovação do processo pedagógico a partir das QSC, na medida em que constataram a mobilização de outras áreas do conhecimento, como o social, o político, o ambiental, entre outros, sendo articulados com conteúdo específico da ciência. Entretanto, de acordo com Aikenhead (2000), o caráter inovador de atividades relacionadas às QSC em sala de

\footnotetext{
${ }^{4}$ Trabalho que aparece pela primeira vez na busca realizada.

${ }^{5}$ Trabalho que aparece pela primeira vez na busca realizada.
} 
aula é muitas vezes percebido pelos professores como um desafio e, consecutivamente, representa um dos principais entraves para a sua implementação.

O desenvolvimento de conteúdos por meio das QSC requer que o docente possa e queira ser desafiado, pois este tipo de abordagem metodológica demanda comprometimento e disposição por parte do professor, a fim de superar dificuldades ou obstáculos que possam aparecer. Mesmo que possam haver alguns obstáculos, existem indicativos que apontam a satisfação docente com o desenvolvimento cognitivo discente, pois é perceptível o aumento da capacidade argumentativa e o interesse dos mesmos pela disciplina escolar (ZEIDLER et al., 2005).

Conforme Levinson (2006), ao estudar a possibilidade de inserir as QSC no currículo das ciências, é necessário considerar algumas questões para as quais o professor precisa estar atento ao planejar suas atividades. Por exemplo, como identificar uma QSC, seu gerenciamento junto aos discentes, quais as possibilidades de aprendizado que eles terão e o que necessitam saber para poder apoderar-se do debate e não se sentirem excluídos do mesmo, pela falta de aporte para argumentação.

Nesta perspectiva, Martínez-Pérez e Carvalho (2012), ao pesquisarem sobre as contribuições e dificuldades da abordagem de QSC, indicam que esta traz um potencial considerável para a prática do professor em termos da tomada de decisão e do progresso do pensamento crítico dos discentes. Entretanto, apontam dificuldades em relação aos aspectos curriculares, pedagógicos e formativos. As dificuldades curriculares estão ligadas ao fato de que o currículo tradicional de ciências restringe a prática docente, impedindo a articulação das QSC com os conteúdos científicos. Sobre as dificuldades pedagógicas, os autores salientam que o Ensino de Ciências centrado nos conteúdos disciplinares impede que professores possam se aprofundar em aspectos sociais, éticos e políticos fundamentais nas QSC. E por fim, sobre as dificuldades formativas, muitos professores não possuem experiência docente necessária para promover a implementação de QSC em sala de aula (SILVA, 2014).

Com relação ao cruzamento dos unitermos QSC e Educação em Ciências, foram obtidos 261 trabalhos que agregam estas temáticas, sendo que após a leitura do resumo e, posteriormente, a leitura completa do trabalho, elegeu-se nove produções, que salientam tópicos relacionados diretamente com essa pesquisa. Os resultados deste cruzamento podem ser observados na tabela 4 e figura 5 .

Tabela 4 - Trabalhos encontrados no cruzamento dos unitermos QSC e Educação em Ciências

\begin{tabular}{cccc}
\hline Fonte & Trabalho por assunto & $\begin{array}{c}\text { Trabalhos após } \\
\text { leitura do resumo }\end{array}$ & $\begin{array}{c}\text { Trabalhos após } \\
\text { leitura completa }\end{array}$ \\
\hline BDTD & 19 & 07 & 06 \\
CTDC & 237 & 12 & 03 \\
SciELO & 00 & 00 & 00 \\
Google & 01 & 01 & 00 \\
ENPEC & 03 & 00 & 00 \\
RBPEC & 01 & 00 & 00 \\
Total & 261 & 20 & 09 \\
\hline
\end{tabular}

Fonte: Elaborado pelos autores (2020). 
Figura 5 - Gráfico obtido através do cruzamento dos unitermos QSC e Educação em Ciências segundo as bases pesquisadas

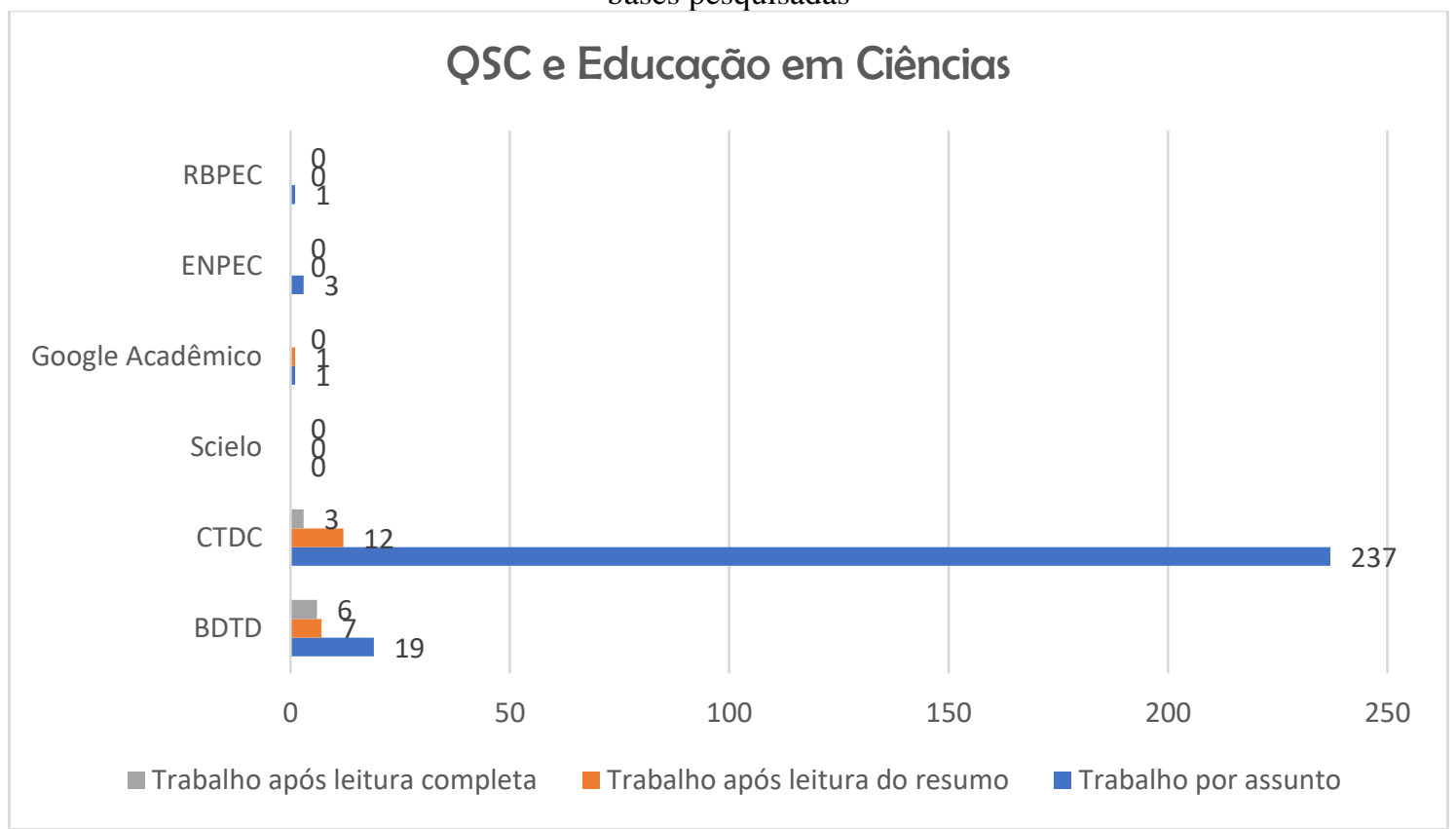

Fonte: Elaborado pelos autores (2020).

A partir do cruzamento dos unitermos QSC e Educação em Ciências, obteve-se as seguintes produções (Quadro 5):

Quadro 5 - Relação de trabalhos escolhidos sobre a temática

\begin{tabular}{|l|l|}
\hline \multicolumn{1}{|c|}{ Trabalhos Selecionados após Leitura Completa } & $\begin{array}{c}\text { Base de Dados - Ano de Publicação - } \\
\text { Autores }\end{array}$ \\
\hline $\begin{array}{l}\text { Compreensões sobre a natureza da ciência de licenciandos a partir da } \\
\text { experiência com questões sociocientíficas: possibilidades para a } \\
\text { formação inicial - Tese }\end{array}$ & $\begin{array}{l}\text { CTDC - 2015 - Diana Fabiola Moreno } \\
\text { Sierra }\end{array}$ \\
\hline A moral em questões sociocientíficas no ensino de biologia - Tese & $\begin{array}{l}\text { BDTD - 2016 - Shirley Margareth Buffon da } \\
\text { Silva }\end{array}$ \\
\hline $\begin{array}{l}\text { Questões Sociocientíficas na Educação CTSA: contribuições de um } \\
\text { modelo teórico para o letramento científico crítico - Tese }\end{array}$ & BDTD - 2017 - Dália Melissa Conrado \\
\hline $\begin{array}{l}\text { Um olhar sobre os processos de apropriação e objetivação da abordagem } \\
\text { de questões sociocientíficas na formação de professores de ciências } \\
\text { naturais - Dissertação }\end{array}$ & $\begin{array}{l}\text { BDTD - 2017 - Wilka Karla Martins do } \\
\text { Vale }\end{array}$ \\
\hline $\begin{array}{l}\text { As questões sociocientíficas na formação de professores: o pequeno } \\
\text { grupo de pesquisa como comunidade de experiência - Tese }\end{array}$ & $\begin{array}{l}\text { CTDC - 2017 - Paulo Gabriel Franco dos } \\
\text { Santos }\end{array}$ \\
\hline $\begin{array}{l}\text { Formação de conceitos da termoquímica em meio a relações CTSA e } \\
\text { questôes sociocientíficas: contribuições da teoria da atividade histórico- } \\
\text { cultural - Tese }\end{array}$ & $\begin{array}{l}\text { BDTD - 2018 - Beatriz Vivian Schneider- } \\
\text { Felicio }\end{array}$ \\
\hline $\begin{array}{l}\text { Propostas de ensino baseado em questões sociocientíficas: uma análise } \\
\text { sistemática da literatura acerca do Ensino de Ciências na educação } \\
\text { básica - Dissertação }\end{array}$ & BDTD - 2018 - Grégory Alves Dionor \\
\hline $\begin{array}{l}\text { Argumentação e raciocínio moral em questões sociocientíficas na } \\
\text { formação de professores de ciências: o exemplo da eutanásia - } \\
\text { Dissertação }\end{array}$ & BDTD - 2018 - Mayara Tavares de Almeida \\
\hline $\begin{array}{l}\text { Abordagem de questões sociocientíficas: buscando relações entre } \\
\text { diferentes modos de pensar e contextos em estudos sobre fármacos e } \\
\text { automedicação no ensino de química - Tese }\end{array}$ & $\begin{array}{l}\text { CTDC - 2018 - Bruna Herculano da Silva } \\
\text { Bezerra }\end{array}$ \\
\hline
\end{tabular}

Fonte: Elaborado pelos autores (2020).

Constata-se que neste último cruzamento entre unitermos não houve o surgimento de trabalhos inéditos com relação às buscas anteriormente realizadas. 
Segundo Laugksch (2000), a função social do letramento científico, disseminado para a Educação em Ciências é justamente que esta promova o entendimento conceitual dos conteúdos das ciências. Em contrapartida, a abordagem de QSC, de acordo com Zeidler et al. (2005) e Sadler (2004), não implica necessariamente em aprendizagem de conteúdos rigorosamente científicos, o que acarreta o debate mais complexo acerca das abordagens QSC em função dos diferentes pontos de vista sobre o que pode e deve ser ministrado no ambiente escolar, colocando sob suspeita a eficiência metodológica da perspectiva QSC. O exposto acarreta falas favoráveis e contrárias no campo da Educação em Ciências quando o assunto diz respeito a inserção das QSC nas aulas desta disciplina.

Sadler e Zeidler (2004) citam alguns dos objetivos que podem ser alcançados com a utilização das QSC, tais como: tornar a aprendizagem científica mais relevante para a vida dos discentes; apreciação sobre a natureza da ciência; na melhoria da argumentação dialógica; na capacidade de avaliar dados científicos e informações; e como um componente importante do letramento científico.

Dos autores que sugerem a incorporação das QSC na Educação em Ciências, temos como exemplo Ratcliffe (1997, p. 4, tradução nossa), que ordenou objetivos de acordo com os seguintes tópicos:

i) relevância: encorajamento dos discentes a associar suas experiências na ciência escolar com problemas da vida real desenvolvendo sua responsabilidade social;

ii) motivação: para explorar ainda mais as ciências como questão de estudo;

iii) comunicação: auxiliando os discentes a se expressar verbalmente, na escuta e na argumentação;

iv) análise: ajudando os discentes nas habilidades de desenvolvimento do raciocínio e pensamento crítico;

v) compreensão: apropriação dos conhecimentos e conceitos científicos.

O quadro 6 apresenta as vantagens e desvantagens do uso de uma estrutura para discussão de QSC

Quadro 6 - Propósitos da discussão das QSC: vantagens e limitações em seu uso como estratégia de ensino na sala de aula

\begin{tabular}{|c|l|l|}
\hline Objetivo & \multicolumn{1}{|c|}{ Vantagem } & \multicolumn{1}{|c|}{ Limitação } \\
\hline Relevância & $\begin{array}{l}\text { - Auxiliar o desenvolvimento de atitudes; } \\
\text { - Dar um contexto real para a ciência escolar. }\end{array}$ & $\begin{array}{l}\text { - O domínio do aluno pela questão pode } \\
\text { ser limitada. }\end{array}$ \\
\hline Motivação & $\begin{array}{l}\text { - Promover uma atividade na qual os estudantes } \\
\text { tenham opiniões e habilidades que sejam valorizados }\end{array}$ & $\begin{array}{l}\text { - A contribuição dos estudantes podem } \\
\text { não ter o devido valor a mesmo que o } \\
\text { resultado ou processo seja revisado. }\end{array}$ \\
\hline Comunicação & $\begin{array}{l}\text { - Claras oportunidades para estudantes verbalizarem e } \\
\text { apresentarem argumentações coerentes; } \\
\text { - A forma como está estruturado previne problemas } \\
\text { comuns de discussões realizadas em grupos. }\end{array}$ & $\begin{array}{l}\text { - Uma quantidade limitada de conversas } \\
\text { fora do contexto, pode acontecer, a } \\
\text { menos que a motivação seja mantida. }\end{array}$ \\
\hline Análise & $\begin{array}{l}\text { - Disposição de uma estrutura que auxilia a ser } \\
\text { sistematicamente analisada. }\end{array}$ & $\begin{array}{l}\text { - O professor tem que explicar } \\
\text { propósitos e passos em análise e avaliar } \\
\text { o processo já que a análise deve ser vista } \\
\text { como sistemática e valorizada. }\end{array}$ \\
\hline $\begin{array}{c}\text { Compreensão } \\
\text { Científica }\end{array}$ & $\begin{array}{l}\text { Os estudantes podem consolidar alguns } \\
\text { conhecimentos existentes com a ajuda do professor. }\end{array}$ & $\begin{array}{l}\text { - Não ú condutor para o ensino de } \\
\text { novas ciências. }\end{array}$ \\
\hline
\end{tabular}
Fonte: Ratcliffe (1997, p. 5; tradução dos autores)

Diversos pesquisadores da área das ciências naturais têm referido a utilização das QSC com vários objetivos para o Ensino de Ciências. Zeilder et al. (2005) qualificaram quatro áreas de importância pedagógica para as QSC, conforme descrito abaixo e apresentado na Figura 6: 
Figura 6 - Elementos sociocientíficos da alfabetização científica funcional

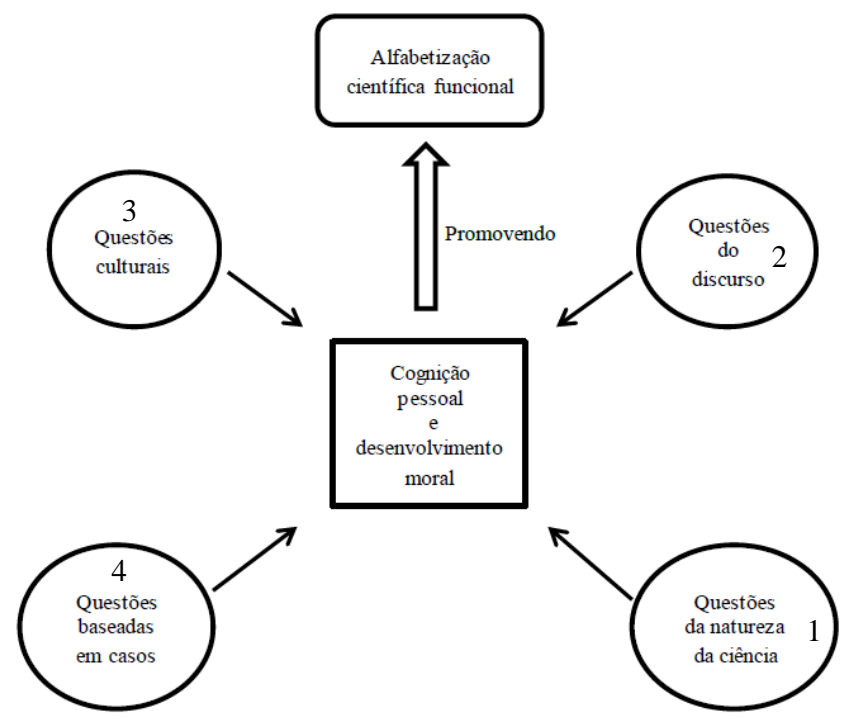

Fonte: Zeidler et al. (2005; tradução dos autores)

(1) questões da natureza da ciência - incluem orientações epistemológicas sobre a natureza e influência da ciência; (2) questões discursivas em sala de aula - enfatizam papel desempenhado pelo discurso nas interações entre pares e seu impacto sobre o raciocínio; (3) questões culturais - destacam-se por apresentar aspectos pluralistas e sociológicos das salas de aula; e (4) questões baseadas em casos - reforçam a posição de que, a fim de formar cidadãos cientificamente letrados deve-se conceber o progresso ético e moral dos discentes e envolver os discentes com questões e problemas que os levem a ponderar e usar tanto seu intelecto como seu caráter (ZEIDLER et al., 2005, p. 361)

Por todo exposto no texto, é aceitável ter uma compreensão que a tomada de decisão e o desempenho da condição de cidadão na vida cotidiana requer $o$ desenvolvimento de pessoas capazes de analisar os dilemas que o crescimento científico e tecnológico tem realizado nesse ambiente, com isso aos debates QSC com enfoque na Educação CTSA atribuem-se um fundamental papel.

\section{Considerações Finais}

Este artigo propôs evidenciar as pesquisas acadêmicas sobre Questões Sociocientíficas (QSC) no período de 2014 até 2018, com o propósito de a partir destas informações, construir um Estado da Arte sobre o assunto. Como considerações dentro do intervalo analisado, enfatizamos que as produções sobre QSC apresentam um número mais expressivo de publicações na busca realizada através do Google Acadêmico. Somente na base mencionada, considerando apenas a busca pela temática QSC, foram encontrados 82 trabalhos, entre artigos, dissertações e teses, o que merece destaque.

Dentre os artigos, dissertações e teses selecionadas, encontram-se aquelas que apresentam levantamentos da produção acadêmica sobre a temática QSC com enfoque na Educação CTSA na Educação em Ciências de determinado período de tempo, 
evidenciam-se as possíveis razões pelas quais as abordagens através das QSC, até este momento, não foram inseridas efetivamente no processo educacional, em particular na formação de professores de Ciências.

Localizam-se pesquisas que pretendem verificar o potencial de determinada metodologia educacional para promover a inserção das QSC e também aquelas que trazem discussões sobre a implantação de processos educativos pautados na perspectiva da Educação CTSA e no tratamento das Questões Sociocientíficas, buscando perceber as estratégias que podem ser usadas pelo professor ao tratar destes assuntos.

Compreender e apropriar-se das QSC, tornando assim, importante que o futuro professor de ciências da natureza tenha uma formação coerente com tal perspectiva, pois sua ação em sala de aula é decorrente de sua epistemologia. Mostrando o debate pelas QSC, no contexto pedagógico, buscando a renovação do currículo escolar, propondo abordar os conhecimentos de modo contextualizado, interdisciplinar, a partir de situações reais, de problemas ou temas que envolvam Questões Socioambientais, Ciência e Tecnologia. E ainda, pesquisas que indicam que a abordagem das QSC no enfoque da Educação CTSA podem potencializar o comprometimento dos estudantes nos estudos sobre as ciências.

Portanto, a finalidade da seleção dos trabalhos apontados no corpus deste artigo, é possibilitar o entendimento do assunto ao qual se refere a pesquisa como um todo, as QSC e suas relações com CTSA, Formação de Professores em Ciências e Educação em Ciências, pois todas as produções evidenciam entre si, dados e informações que entrelaçam estas temáticas, trazendo maior clareza ao estudo.

E para concluir, ressaltamos que o fato que requer maior atenção é que para toda essa pesquisa realizada, nas bases de dados utilizadas, BDTD, CTDC, Scielo, Google Acadêmico, ENPEC e a Revista Brasileira de Pesquisa em Educação em Ciências (RBPEC) não foram encontrados trabalhos que trouxessem o cruzamento dos quatros unitermos (QSC, CTSA, Formação de Professores de Ciências e Educação em Ciências), houve no máximo trabalhos que traziam apontamentos sobre duas ou três das temáticas juntas, mas com as quatro não foi encontrado nenhum trabalho, o que torna ainda mais instigante e oportuna a proposta da qual este artigo é parte integrante, como Estado da Arte, que é o de reconhecer e compreender se a formação docente dos professores de Ciências da Natureza permite aos mesmos que proponham suas aulas utilizando as QSC com enfoque na Educação CTSA, para a melhoria da capacidade de mobilização de conteúdos e da formação de cidadãos críticos e responsáveis pela sociedade da qual são parte integrante.

\section{Referências}

AIKENHEAD, G. S. Renegotiating the Culture of School Science. In: MILLAR, R.; LEACH, J.; OSBORNE, J.(Orgs.). Improving science education: The contribution of research. Birmingham: Open University Press, 2000. p. 245-264.

BAPTISTA, D. M. T. O Debate Sobre o Uso de Técnicas Qualitativas e Quantitativas de Pesquisa. In: MARTINELLI, M. L. (Org.). Pesquisa Qualitativa: Um Instigante Desafio. São Paulo: Veras, 1999. p.34 
BERNARDO, J. R. R. Limites e Possibilidades para a Abordagem de Questões Sociocientíficas na Visão do Professor de Física da Educação Básica. Revista Enseñanza de las Ciencias, v. extra organizado pelo IX Congreso Internacional Sobre Investigación en Didáctica de las Ciencias, p. 376-380, 2013.

GAMBOA, S. S. Epistemologia da Pesquisa em Educação: Estruturas Lógicas e Tendências Metodológicas. n.f. 1987. Tese (Doutorado em Educação) - Universidade Estadual de Campinas, Campinas: [s.n], 1987.

LAUGKSCH, R.C. Scientific Literacy: A Conceptual Overview. Science Education, v. 84, n.1, p. 74-94, 2000.

LEVINSON, R. Towards a Theoretical Framework for Teaching Controversial Socioscientific Issues. International Journal of Science Education, v. 28, n. 10, p. 12011224, 2006.

MARTÍNEZ-PÉREZ, L. F.; CARVALHO, W L. P. (2012). Contribuições e

Dificuldades da Abordagem de Questões Sociocientíficas na Prática de Professores de Ciências. Educação e Pesquisa, v. 38, n. 3, p. 727-741, 2012.

MARTÌNEZ PÉREZ, L. F. Questões Sociocientíficas na Prática Docente: Ideologia, Autonomia e Formação de Professores. São Paulo, Editora UNESP, 2012.

MEGID NETO, J. Tendências da Pesquisa Acadêmica sobre Ensino de Ciências no Nível Fundamental. n.f. 1999. Tese (Doutorado em Educação). Universidade Estadual de Campinas, Campinas: [s.n], 1999.

OULTON, C., DILLON, J. e GRACE, M. Reconceptualising the Teaching of Controversial Issues. International Journal of Science Education, v. 26, n. 4, p. 411423, 2004.

RATCLIFFE, M. Discussing Socio-Scientific Issues in Science Lessons - Pupils Actions and the Teacher's Role. School Science Review, v. 79, n. 288, p. 04-05, 1997.

SADLER, T. D. Informal Reasoning Regarding Socioscientific Issues: A Critical Review of Research. Journal of Research in Science Teaching, v. 41, n. 5 , p. 513 536, 2004.

SADLER, T. D.; ZEIDLER, D. L. The Morality of Socioscientific Issues Construal and Resolution of Genetic Engineering Dilemmas. Science Education, v. 88, n. 1, p. 4-27, 2004.

SANTOS, W. L. P. dos. Aspectos Sociocientíficos em Aulas de Química. n.f. 2002. Tese (Doutorado em Educação) - Faculdade de Educação da Universidade Federal de Minas Gerais, Belo Horizonte: [s.n], 2002.

SILVA, K. M. A. Questões Sociocientíficas e o Pensamento Complexo: Tecituras para o Ensino de Ciências. n.f. 2016. Tese (Doutorado em Educação) - Faculdade de Educação, Brasília: [s.n], 2016. 
SILVA, V. H. D. Limites e Possibilidades na Inserção de Questões Sociocientíficas: Um Estudo com Professores da Educação Básica. 2014. Dissertação (Mestrado em Educação) - Universidade Federal Fluminense. Rio de Janeiro.

TAL, T.; KEDMI, Y. Teaching Socioscientific Issues: Classroom Culture and Students' Performances. Cultural Studies of Science Education, v.XX, n., XX, p. XX-XX, ano.

ZEIDLER, D. L.; SADLER, T. D.; SIMMONS, M. L.;HOWES, E. V. Beyond STS: A Research-Based Framework for Socioscientific Issues Education. Science Education, v. 89, n. 3 , p. 357-377, 2005.

Recebido em novembro de 2019.

Aprovado em maio de 2020. 